\title{
Overexpression of the Six1 Homeobox Gene Is Associated with Diffuse Peritoneal Spread and Larger Residual Disease after Maximal Cytoreductive Effort in Advanced Ovarian Cancer
}

\author{
Julia R. Embry-Schubert1, Lubna Qamar², Monique Spillman³, Michael G. Kelly4, \\ Susan A. Davidson ${ }^{5}$, Kian Behbakht ${ }^{2 *}$ \\ ${ }^{1}$ Department of Obstetrics and Gynecology, Kaiser-Permanente, Denver, CO, USA \\ ${ }^{2}$ Division of Gynecologic Oncology, Department of Obstetrics and Gynecology, University of Colorado School \\ of Medicine and Anschutz Medical Campus, Aurora, CO, USA \\ ${ }^{3}$ Texas Oncology Sammons Cancer Center, Baylor University Medical Center, Dallas, TX, USA \\ ${ }^{4}$ Wake Forest University School of Medicine, One Medical Center Boulevard, Winston-Salem, NC, USA \\ ${ }^{5}$ Denver Health Medical Center, Denver, CO, USA \\ Email: *kian.behbakht@ucdenver.edu
}

Received 20 October 2015; accepted 30 November 2015; published 3 December 2015

Copyright (C) 2015 by authors and Scientific Research Publishing Inc.

This work is licensed under the Creative Commons Attribution International License (CC BY). http://creativecommons.org/licenses/by/4.0/

(c) (i) 0pen Access

\section{Abstract}

Study Design: Between January 2003 and June 2009, we collected fresh tumor and extracted highquality RNA from the omental/peritoneal metastases of 47 patients with stage IIB-IV ovarian cancer. Clinical data were abstracted from the patients' medical records. Expression of Six1 level by quantitative RT-PCR was compared with preoperative factors and intraoperative findings using the $\chi^{2}$ test and the Fisher exact test. The effect of Six 1 elevation on survival was assessed with the Kaplan/Meier method. Results: The mean age of patients enrolled was 60 (range 33 - 84). The histological subtypes were $77 \%$ serous $(36 / 47), 11 \%$ endometrioid $(5 / 47), 4 \%$ mucinous $(2 / 47)$, and 4\% clear cell (2/47). Eighty-one percent were optimally cytoreduced. Median Six1 expression for the samples was $114 \mathrm{fg} / \mathrm{ng} 18 \mathrm{~S}$ rRNA and Six1 overexpression, defined as $>300 \mathrm{fg} / \mathrm{ng} \mathbf{1 8 S} \mathrm{rRNA}$, was observed in $19 \%$ of tumors. Six 1 expression above sample median was associated with peritoneal disease $(p=0.049)$ and inability to optimally cytoreduce $(p=0.02)$. Six1 overexpression was associated with worsened survival in the high grade serous subgroup (43 months versus 71 months, $p=0.039$ Log Rank test). Conclusions: Elevated levels of Six1 predict peritoneal disease 
and larger residual tumor after maximal cytoreductive effort. Prospective prediction of surgical cytoreduction using a combination of Six1 expression, included with other factors, is currently being evaluated.

\section{Keywords}

\section{Ovarian Cancer, Homeobox Genes, Six1, Cytoreduction}

\section{Introduction}

Ovarian cancer is the deadliest gynecologic cancer in the United States. In 2015, the American Cancer Society estimated that approximately 21,290 women will be newly diagnosed with ovarian carcinoma, and approximately 14,180 women will succumb to this disease [1]. According to the International Federation of Gynecology and Obstetrics (FIGO) staging classification the majority of these newly diagnosed women will have advanced-stage disease (stage III and IV) at the time of diagnosis [2]. Current treatment for advanced stage epithelial ovarian cancer includes maximal surgical cytoreductive effort (to $\leq 1 \mathrm{~cm}$ of residual disease, optimal cytoreduction), followed by combination chemotherapy with platinum/taxane [3]. However, optimal cytoreduction is not always accomplished, whether due to biological or technical factors, resulting in decreased survival.

Homeodomain-containing proteins act as transcription factors that regulate the coordinated expression of genes, involved in development and differentiation, and that are frequently inappropriately expressed in cancer [4] [5]. Six1 (Sine Oculis (so) homolog) belongs to a subfamily of the Six class of homeodomain-containing transcription factors and is an important developmental regulator that is necessary for the proliferation of precursor cell populations during formation of the muscle, eye, kidney, and inner ear, among other organs [5]-[7]. Originally identified as members of the retinal determination network in Drosophila, Sine Oculis and its co-activators such as Drosophila Eye Absent (eya), were shown to function in altogether different contexts in the developing embryo of higher organisms. These include myogenesis [8], gonadogenesis [9] [10], neurogenesis [11], limb development [12], renal and ear development [13] and cell cycle control [14]-[16].

Six1 is aberrantly expressed in an increasing number of human cancers, where its proliferative and antiapoptotic developmental effects often result in advanced stage, treatment resistance, and poor survival. These cancers include rhabdomyosarcomas as well as breast, ovarian, pancreatic, lung, and hepatocellular carcinomas [15] [17]-[22]. When Six1 is expressed outside of normal development, it appears to impart an increase in proliferation and metastasis and a decrease in basal and TRAIL-mediated apoptosis [5] [16]-[18] [23]. Hence, abnormal activity of the Six1 (Sine Oculis (so) homolog)/Eya cofactor embryonic development pathway is an important modulator of carcinogenesis and metastasis in a multitude of human cancers [24]. Given its importance in globally promoting proliferation, decreasing apoptosis, and promoting metastases, we hypothesized that the clinical features and pattern of metastases might be different between Six1 in over expressing advanced ovarian cancers as compared to those that do not over express Six1. Identification of the negative effect of Six1 would provide further rationale for selective patient treatment with factors that inhibit Six1/Eya pathway [25]. The objective of this manuscript is to compare the clinical features and patterns of metastases in Six1 over expressing tumors to those that do not over express Six, and to support the rationale for pursing Six1/Eya inhibitor therapy.

\section{Methods}

Between January 2003 and June 2009, we collected fresh tumor samples and extracted high-quality RNA from the omental or peritoneal metastases of 47 patients with stages IIB - IV ovarian cancer under an IRB approved protocol. Patients' history, surgical staging, residual tumor amount, disease sites, pathology reports, CA-125 levels, preoperative albumin levels, and preoperative computed tomography (CT) scan reports were retrospectively extracted from the patients' medical records. Data collected from the CT scan reports included retroperitoneal lymphadenopathy $(>2 \mathrm{~cm})$, bulky omental disease, any upper abdominal spread $(>2 \mathrm{~cm})$, liver parenchymal spread $(>1 \mathrm{~cm})$, or mention of ascites. 
All patients had a preoperative diagnosis of ovarian cancer and underwent an exploratory laparotomy with the intent of performing total abdominal hysterectomy (when the uterus was present), bilateral salpingo-oophorectomy, omentectomy, and aggressive tumor cytoreduction. Staging was performed by one of four authors. (S.D., K.B., M.S., or M.K.). Aggressive cytoreduction was routinely performed including use of the Cavitron Surgical Aspirator (CUSA; Cavitron, Inc., Stamford, CT). All pathology had been previously reviewed by our institution's gynecologic pathologist.

The operative reports were reviewed and patients' metastatic patterns at the time of exploratory surgery were grouped. Specifically, we recorded small bowel mesenteric involvement causing diffuse small bowel obstruction, diffuse peritoneal spread above the pelvic brim (nodules numbering in the hundreds), lymphatic spread as documented by positive histology, ascites $(>500 \mathrm{~mL}$ ), any visible/clinically suspicious omental involvement, and any visible/clinically suspicious diaphragmatic disease.

Fresh tissue specimens were obtained after gross evaluation and stored in RNA later stabilization buffer (Qiagen). Total RNA was extracted using standard TRIzol extraction (Invitrogen/Life Technologies, Carlsbad, CA). Purity, concentration, and integrity of total RNA were verified using a spectrophotometer as well as the RNA 6000 Nano assay (Agilent Technologies, Palo Alto, CA) and visualization of the 18S and 28S rRNA bands. For quantitative RT-PCR, $1 \mu \mathrm{g}$ of extracted RNA was analyzed by rRNA amplification to verify integrity of the RNA. High-quality specimens were then analyzed for Six1 mRNA levels using the ABI Prism 7700 sequence detection system (Applied Biosystems, Foster City, CA) and Six1-specific primers and Taqman probes. Results are reported as fg Six1/ng 18S rRNA. The sequence of primers utilized (from 5'-3') was sense, CAC CTC CCC AAA GTC CAG AC, antisense, CCT GGC GTG GCC CAT A, and the probe sequence was CGG TCC TTC TGC TGC AGG GCA T.

Expression of Six1 level by Quantitative RT-PCR was recorded as fg Six1/ng 18S rRNA and was compared at a median cut-off and at a cut-off of $300 \mathrm{fg}$ Six $1 / \mathrm{ng} 18 \mathrm{~S}$ rRNA with the metastatic groupings using the $\chi^{2}$ test, and the Fisher exact test. Survival analysis was via the Kaplan-Meier method with comparisons using the LogRank test.

\section{Results}

Demographic and clinical data are shown in Table 1. Mean age was 60 years (range 33 - 84 years) and all but 5 of the patients had stage IIIC or stage IV tumors. The histological subtypes included 77\% serous (36/47), $11 \%$ endometrioid (5/47), $4 \%$ mucinous (2/47), and $4 \%$ clear cell (2/47). Of the two remaining patients, one tumor was subsequently reviewed as serous low grade and another was an undifferentiated carcinoma. All but 4 of the patients had elevated CA-125 levels, above our laboratory cutoff of $>35 \mathrm{U} / \mathrm{mL}$, with a mean CA125 of 1061 $\mathrm{U} / \mathrm{mL}$ (range $21 \mathrm{U} / \mathrm{mL}$ to $5217 \mathrm{U} / \mathrm{mL}$ ).

The majority of the surgeries 34/47 (73\%) were performed by the senior author. There was no difference in the rates of optimal cytoreduction between the four surgeons. Thirty eight $(81 \%, 38 / 47)$ of the patients were optimally cytoreduced to less than $1 \mathrm{~cm}$ residual disease. Four patients either refused treatment or died without completing treatment and an additional 3 were lost to followup after treatment. Of all patients, 24 (24/47, 51\%) were platinum sensitive with progression free interval of greater than 12 months after finishing treatment and an additional 7 (7/47, 15\%) were platinum sensitive with a progression free interval of 6 - 12 months. Four (4/47, $8 \%)$ were platinum resistant and $5(5 / 47,11 \%)$ were platinum refractory. Recurrences were identified in 25 (25/47, 53\%) of patients with the median time to recurrence of 15 months.

Both Six1 mRNA sample median of $114 \mathrm{fg} / \mathrm{ng} 18 \mathrm{~S}$ rRNA and a higher cut-off of $>300 \mathrm{fg} / \mathrm{ng} 18 \mathrm{~S}$ rRNA, previously shown by us to have prognostic significance [17] [26], were used for analysis. Six1 overexpression by mRNA > $300 \mathrm{fg} / \mathrm{ng} 18 \mathrm{~S}$ rRNA was seen in $9(9 / 47,19 \%)$ of tumor specimens. Six1 mRNA levels above versus at or below sample median were compared to the presence or absence of preoperative CT variables (Table 2) and intraoperative variables (Table 3). Additionally, a matrix table of Six1 levels with median cut-off and >300 fg/ng 18S rRNA cutoff together with cytoreduction $<1 \mathrm{~cm}$ status, and intraoperative assessments of mesenteric involvement, diffuse peritoneal spread, omental spread, ascites $>500 \mathrm{cc}$, and diaphragmatic spread for all patients is shown in Figure 1. Elevated Six1 above sample median of $114 \mathrm{fg} / \mathrm{ng} 18 \mathrm{~S}$ rRNA was significantly associated with surgical findings of diffuse peritoneal spread ( $p=0.049, \chi^{2}$ test) and inability to cytoreduce to less than $1 \mathrm{~cm}\left(\mathrm{p}=0.02, \chi^{2}\right.$ test). Six1 elevation above the sample median was not associated with frequency of recurrences or recurrence free interval, with platinum sensitivity, or with any other preoperative CT 
Table 1. Demographic and clinical characteristics of the study population $(n=47)$, FIGO = International Federation of Gynecology and Obstetrics; PFI = Progression Free Interval.

\begin{tabular}{|c|c|}
\hline Variable & $\mathrm{n}=47(\%)$ \\
\hline Median age (range) & 60 yrs (33 - 84 yrs) \\
\hline \multicolumn{2}{|l|}{ Histology } \\
\hline High grade serous & $36(77 \%)$ \\
\hline Mucinous & $2(4 \%)$ \\
\hline Endometrioid & $5(11 \%)$ \\
\hline Clear cell & $2(4 \%)$ \\
\hline Low grade serous & $1(2 \%)$ \\
\hline Undifferentiated & $1(2 \%)$ \\
\hline Mean preoperative CA125 (range) & $1061 \mathrm{U} / \mathrm{mL}(21-5217 \mathrm{U} / \mathrm{mL})$ \\
\hline Mean preoperative albumin (range) & 3.3 g/dL (1.4 - 4.7 g/dL) \\
\hline \multicolumn{2}{|l|}{ FIGO stage } \\
\hline IIb & $3(7 \%)$ \\
\hline IIIa & $2(4 \%)$ \\
\hline IIIb & $0(0 \%)$ \\
\hline IIIc & $33(70 \%)$ \\
\hline IV & $9(19 \%)$ \\
\hline Cytoreduced to less than $1 \mathrm{~cm}$ & $38(81 \%)$ \\
\hline \multicolumn{2}{|l|}{ Platinum sensitivity } \\
\hline Platinum sensitive $>12$ months PFI & $24(51 \%)$ \\
\hline Platinum sensitive 6 - 12 months PFI & $7(15 \%)$ \\
\hline Platinum resistant & $4(8 \%)$ \\
\hline Platinum refractory & $5(11 \%)$ \\
\hline Unknown/Insufficient information & 7 (15\%) \\
\hline Median follow up (range) & 31 months (0.4 - 104 months) \\
\hline Number of recurrences & $25(53 \%)$ \\
\hline Lost to follow up & 7 (15\%) \\
\hline Median months to recurrence (range) & 15 months ( 0 - 104 months) \\
\hline
\end{tabular}

Table 2. Percentage of study patients with CT findings: comparison of Six1 less than or equal to sample median (low Six1) versus Six1 greater than sample median (high Six1). CT = computed tomography; NS = not significant; *Reports were available in $42 / 47$ patients; **1 additional patient had ascites on CT scan but no other documented findings.

\begin{tabular}{|c|c|c|c|c|}
\hline CT scan variable & All patients & Low Six1 & High Six1 & Significance \\
\hline & $\mathrm{n}=42 *$ & $\mathrm{n}=19$ & $n=23$ & \\
\hline Ascites & $34 / 43 * *(79 \%)$ & $14(74 \%)$ & $20 / 24 * *(83 \%)$ & NS \\
\hline Lymphadenopathy & $9(21 \%)$ & $6(32 \%)$ & $3(13 \%)$ & NS \\
\hline Omental spread & $18(43 \%)$ & $8(42 \%)$ & $10(43 \%)$ & NS \\
\hline Any upper abdominal spread & $11(26 \%)$ & $3(16 \%)$ & $8(35 \%)$ & NS \\
\hline Hepatic parenchymal spread & $4(9 \%)$ & $1(5 \%)$ & $3(13 \%)$ & NS \\
\hline Mesenteric spread & $8(19 \%)$ & $3(16 \%)$ & $5(22 \%)$ & NS \\
\hline
\end{tabular}




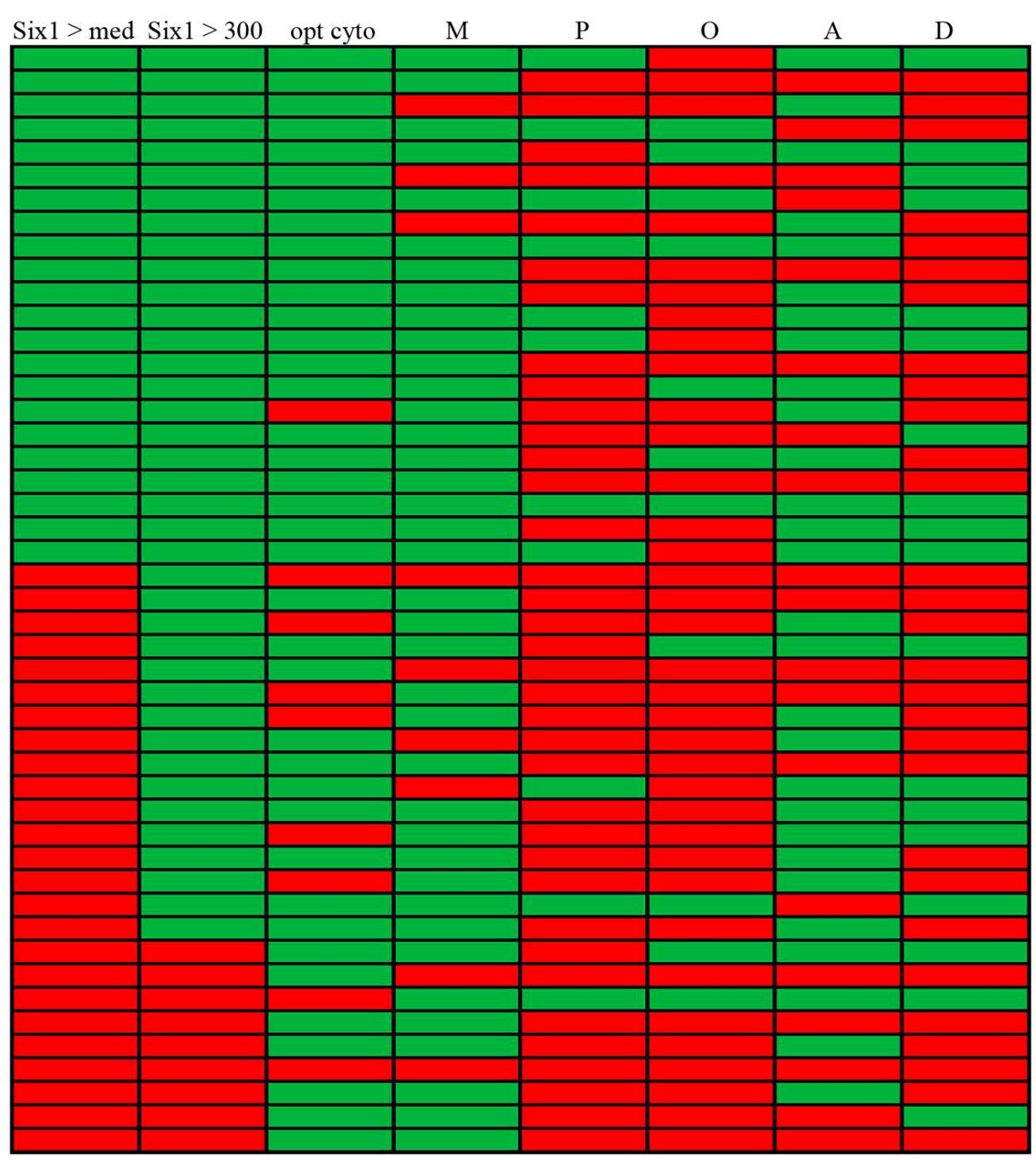

Figure 1. Matrix table of increasing Six1 levels with median cut-off (med) and $>300 \mathrm{fg} / \mathrm{ng} 18 \mathrm{~S}$ rRNA cutoff together with cytoreduction (opt cyto) $<1 \mathrm{~cm}$ status, mesenteric involvement (M), diffuse peritoneal spread $(\mathrm{P})$, omental spread $(\mathrm{O})$, ascites $>500 \mathrm{cc}(\mathrm{A})$ and diaphragmatic spread (D). No = green, Yes = red for all variables, each row represents one patient in the dataset.

Table 3. Percentage of patient with findings at surgery: comparison of Six1 less than or equal to sample median (low Six1) versus Six1 greater than sample median (high Six1). NS = not significant; $* 31$ of the patients did not have this intraoperative finding documented.

\begin{tabular}{ccccc}
\hline Intraoperative findings & All patients & Low Six1 & High Six1 & Significance \\
\hline >500 cc ascites & $\mathrm{n}=47$ & $\mathrm{n}=22$ & $\mathrm{n}=25$ & \\
Malignant lymphadenopathy & $19(40 \%)$ & $8(36 \%)$ & $11(44 \%)$ & NS \\
Omental spread & $8(34 \%)^{*}$ & $3(14 \%)$ & $5(20 \%)$ & NS \\
Diffuse peritoneal spread & $36(77 \%)$ & $15(68 \%)$ & $21(84 \%)$ & NS \\
Mesenteric disease & $36(77 \%)$ & $14(64 \%)$ & $22(88 \%)$ & $\mathrm{p}=0.049$ \\
Diaphragmatic disease & $9(19 \%)$ & $3(14 \%)$ & $6(24 \%)$ & NS \\
Number cytoreduced to less than 1 cm residual disease & $38(81 \%)$ & $21(95 \%)$ & $17(68 \%)$ & p $=0.02$ \\
\hline
\end{tabular}


(Table 2) or intraoperative disease pattern (Table 3) variable.

At a median follow-up of 31 months for the entire cohort, 21 (21/47, 45\%) of the patients have died with disease. Elevated Six1 at a cutoff of $>300 \mathrm{fg} / \mathrm{ng} 18 \mathrm{~S}$ rRNA was associated with significantly worsened mean survival for the high grade serous tumors (71 months versus 43 months, $p=0.039$ Log Rank, Kaplan-Meier curves shown as Figure 2) and showed a trend towards worsened survival for the entire group (63 months versus 43 months, $\mathrm{p}=0.08$ Log Rank, Kaplan-Meier curves shown as Figure 3). Six1 expression at greater than $300 \mathrm{fg} / \mathrm{ng}$ $18 \mathrm{~S}$ rRNA was not associated with platinum resistance, presence of recurrence, or time to recurrence.

\section{Discussion}

We have shown that expression of Six1 mRNA above the sample mean of $>114 \mathrm{fg} / \mathrm{ng} 18 \mathrm{~S}$ rRNA predicts diffuse

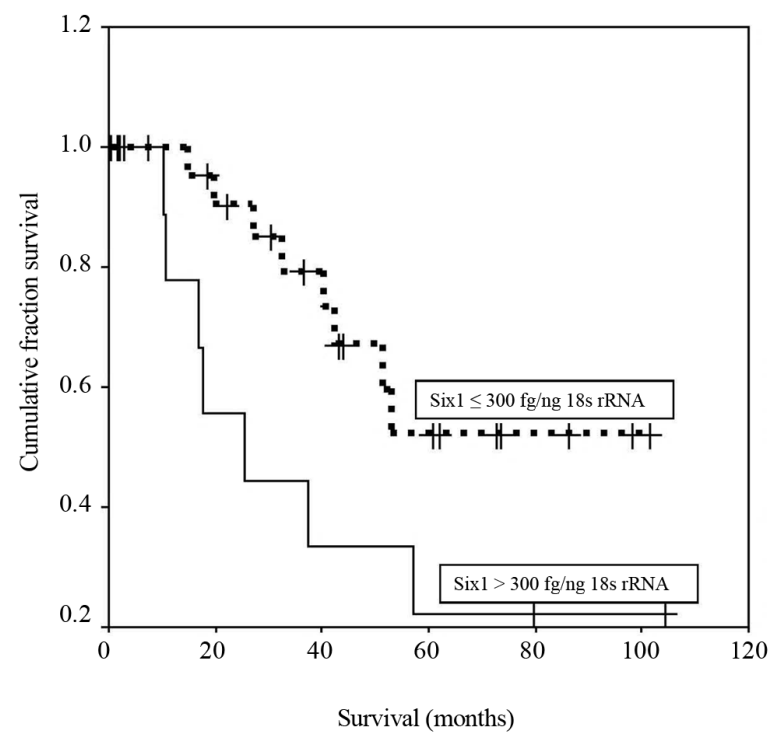

Figure 2. Kaplan-Meier survival for patients with high grade serous cancer (Six $1>300 \mathrm{fg} / \mathrm{ng} 18 \mathrm{~S}$ rRNA vs Six $1 \leq$ $300 \mathrm{fg} / \mathrm{ng} 18 \mathrm{~S}$ rRNA) $\mathrm{p}=0.039$ Log Rank.

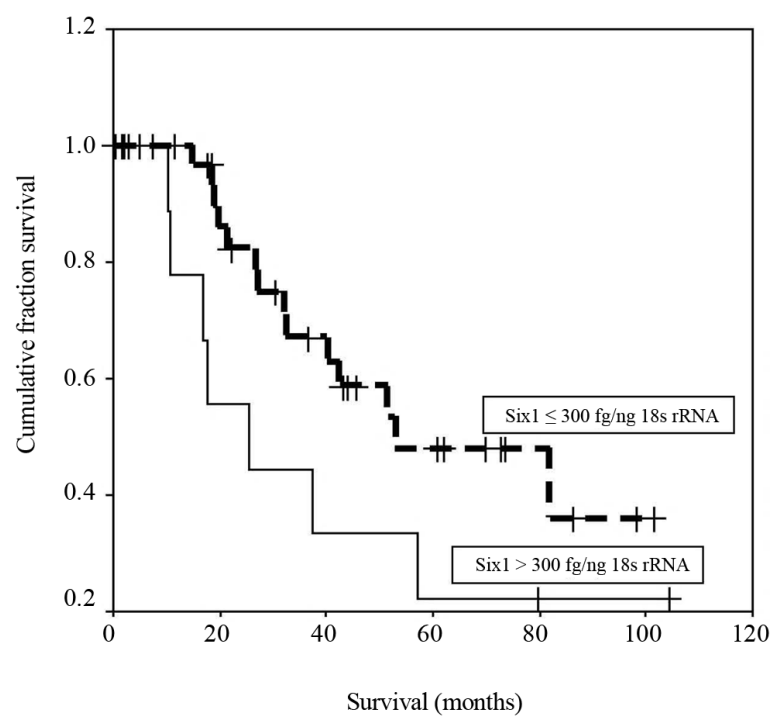

Figure 3. Kaplan-Meier survival for all patients (Six1 > 300 fg/ng $18 \mathrm{~S}$ rRNA vs Six $1 \leq 300 \mathrm{fg} / \mathrm{ng} 18 \mathrm{~S}$ rRNA) $\mathrm{p}=0.08$ Log Rank. 
peritoneal disease and a larger amount of residual tumor after maximal cytoreductive effort. While expression at this level did not correlate with a significantly worse survival, Six1 expression $>300 \mathrm{fg} / \mathrm{ng} 18 \mathrm{~S}$ rRNA did correlate with worse survival. This parallels our earlier findings where features of malignancy and advanced stage were seen at levels $>100 \mathrm{fg} / \mathrm{ng} 18 \mathrm{~S}$ rRNA but worsened survival in advanced stage tumors (and independent of advanced stage) was seen at levels $>300 \mathrm{fg} / \mathrm{ng}$ 18S rRNA [17] [26]. However, it is not clear what additional carcinogenic events occur between the sample median cut-off of Six1 as opposed to the higher expression level associated with poor prognosis.

Analysis of Six1 RNA using RNA seq V2 data from the TCGA high grade serous ovarian cancer provisional dataset on www.cbioportal.org shows a trend $(p=0.07)$ for Six1 overexpression (relative expression, $z$-score \pm 2 ) towards poor survival in a 479 patient multi-institution dataset [27]. More broadly, Six1 expression is a poor prognostic factor for survival in cancers as diverse as oligodendroglioma and breast cancer [28]. Because these diverse cancers likely do not share similar genetic profiles, the mechanism responsible for the poor prognosis observed with Six1 overexpression may be multifactorial and tissue dependent. In a model in which human breast cancer cells were injected into immune-compromised mice, Six1 expression promoted peritumoral and intratumoral lymphangiogenesis, lymphatic invasion, and distant metastasis of breast cancer cells [29]. We did not find a higher incidence of lymph node metastases in our sample of patients whose tumors overexpressed Six1. This may be due to undersampling, because it is not our routine practice to remove lymph nodes when the cancer is already staged as IIIC (evidence of metastasis $>2 \mathrm{~cm}$ above the pelvic brim). Also, since ovarian cancer predominantly spreads via intraperitoneal dissemination, it is possible that the effect of a factor promoting lymph node metastases is not as important in ovarian cancer as opposed to breast cancer.

In another study, expression of Six1 in breast cancer cell lines MCF-7 and HS578T correlated with resistance to paclitaxel, and knockdown of endogenous Six1 in Six1-high/drug-resistant BT-474 breast cancer cells sensitized to paclitaxel. Additionally, Six1 over expression conferred resistance to paclitaxel-mediated apoptosis [30]. In our report, we did not find any relation to clinical chemosensitivity, however our measure of sensitivity was to combination platinum and taxane, and was measured by convention as the platinum free interval. It is not possible to isolate selective taxane resistance from this clinical cohort.

Our prior publication identified diffuse peritoneal studding as the most important risk factor for calculating a surgical risk score predicative of suboptimal cytoreduction [31]. The current manuscript shows Six1 expression as associated with diffuse peritoneal spread and also with suboptimal cytoreduction. Since Six1 affects metastases in many model systems [24] [32], it is possible that Six1 expressing tumors have a predilection for diffuse peritoneal metastases and hence the association with suboptimal cytoreduction. In the prior study we also found abdominal mesenteric disease and para-aortic lymphadenopathy as predictors of suboptimal cytoreduction, (albeit with a lower risk coefficient) and these factors were not associated with elevated Six1 in the current study.

There are several limitations to our study. While we did not use upfront selection criteria for the patients included in the study, the retrospective nature of this report does raise the potential of selection bias. Additionally, not all patients had a lymph node sampling, making the interpretation of lymph node data problematic. As a factor in a predictive model, Six1 assessment of the tumor is currently too invasive (via tumor biopsy) unless it can be performed on ascites or via phenotypic assessment of enriched circulating tumor cells (CTCs). The latter is a possibility as immunohistochemistry has been performed on CTCs from ovarian cancer patients [33].

\section{Conclusion}

The treatment of ovarian cancer continues to be a challenge. Knowledge of the genetic defects resulting in ovarian tumorigenesis has allowed basic and translational findings to result in novel patient treatments, although with a lag. Here we continue to show the poor prognostic effect of the Six1 homeobox gene in ovarian cancer. Since Six 1 is ordinarily not expressed in adult tissues outside of malignancies, its inhibition has the potential to be an effective and nontoxic novel therapy for ovarian cancer.

\section{Acknowledgements}

We would like to acknowledge Dr. Heide L. Ford for critical reading of the manuscript.

\section{Funding}

This work was supported by Department of Defense Idea Award \#OC06143 (KB). 


\section{Conflict of Interests}

The authors declare that there are no conflicts of interest.

\section{References}

[1] Siegel, R.L., Miller, K.D. and Jemal, A. (2015) Cancer Statistics, 2015. CA: A Cancer Journal for Clinician, 65, 5-29. http://dx.doi.org/10.3322/caac.21254

[2] Heintz, A.P., Odicino, F., Maisonneuve, P., et al. (2006) Carcinoma of the Ovary. FIGO 6th Annual Report on the Results of Treatment in Gynecological Cancer. International Journal of Gynecology and Obstetrics, 95, S161-S192. http://dx.doi.org/10.1016/s0020-7292(06)60033-7

[3] Morgan Jr., R.J., Alvarez, R.D., Armstrong, D.K., et al. (2013) Ovarian Cancer, Version 2. 2013. Journal of the National Comprehensive Cancer Network, 11, 1199-1209.

[4] Abate-Shen, C. (2002) Deregulated Homeobox Gene Expression in Cancer: Cause or Consequence? Nature Reviews Cancer, 2, 777-785. http://dx.doi.org/10.1038/nrc907

[5] Li, X., Oghi, K.A., Zhang, J., et al. (2003) Eya Protein Phosphatase Activity Regulates Six1-Dach-Eya Transcriptional Effects in Mammalian Organogenesis. Nature, 426, 247-254. http://dx.doi.org/10.1038/nature02083

[6] Zheng, W., Huang, L., Wei, Z.B., et al. (2003) The Role of Six1 in Mammalian Auditory System Development. Development, 130, 3989-4000. http://dx.doi.org/10.1242/dev.00628

[7] Ozaki, H., Nakamura, K., Funahashi, J., et al. (2004) Six1 Controls Patterning of the Mouse Otic Vesicle. Development, 131, 551-562. http://dx.doi.org/10.1242/dev.00943

[8] Heanue, T.A., Reshef, R., Davis, R.J., et al. (1999) Synergistic Regulation of Vertebrate Muscle Development by Dach2, Eya2, and Six1, Homologs of Genes Required for Drosophila Eye Formation. Genes \& Development, 13, 3231-3243. http://dx.doi.org/10.1101/gad.13.24.3231

[9] Bai, J. and Montell, D. (2002) Eyes Absent, a Key Repressor of Polar Cell Fate during Drosophila Oogenesis. Development, 129, 5377-5388. http://dx.doi.org/10.1242/dev.00115

[10] Fabrizio, J.J., Boyle, M. and DiNardo, S. (2003) A Somatic Role for Eyes Absent (Eya) and Sine Oculis (so) in Drosophila Spermatocyte Development. Developmental Biology, 258, 117-128. http://dx.doi.org/10.1016/S0012-1606(03)00127-1

[11] Li, X., Perissi, V., Liu, F., et al. (2002) Tissue-Specific Regulation of Retinal and Pituitary Precursor Cell Proliferation. Science, 297, 1180-1183. http://dx.doi.org/10.1126/science.1073263

[12] Xu, P.X., Cheng, J., Epstein, J.A. and Maas, R.L. (1997) Mouse Eya Genes Are Expressed during Limb Tendon Development and Encode a Transcriptional Activation Function. Proceedings of the National Academy of Sciences of the United States of America, 94, 11974-11979. http://dx.doi.org/10.1073/pnas.94.22.11974

[13] Xu, P.X., Adams, J., Peters, H., et al. (1999) Eya1-Deficient Mice Lack Ears and Kidneys and Show Abnormal Apoptosis of Organ Primordia. Nature Genetics, 23, 113-117. http://dx.doi.org/10.1038/12722

[14] Kurusu, M., Nagao, T., Walldorf, U., et al. (2000) Genetic Control of Development of the Mushroom Bodies, the Associative Learning Centers in the Drosophila Brain, by the Eyeless, Twin of Eyeless, and Dachshund Genes. Proceedings of the National Academy of Sciences of the United States of America, 97, 2140-2144. http://dx.doi.org/10.1073/pnas.040564497

[15] Ford, H.L., Kabingu, E.N., Bump, E.A., et al. (1998) Abrogation of the G2 Cell Cycle Checkpoint Associated with Overexpression of HSIX1: A Possible Mechanism of Breast Carcinogenesis. Proceedings of the National Academy of Sciences of the United States of America, 95, 12608-12613. http://dx.doi.org/10.1073/pnas.95.21.12608

[16] Coletta, R.D., Christensen, K., Reichenberger, K.J., et al. (2004) The Six1 Homeoprotein Stimulates Tumorigenesis by Reactivation of Cyclin A1. Proceedings of the National Academy of Sciences of the United States of America, 101, 6478-6483. http://dx.doi.org/10.1073/pnas.0401139101

[17] Behbakht, K., Qamar, L., Aldridge, C.S., et al. (2007) Six1 Overexpression in Ovarian Carcinoma Causes Resistance to TRAIL-Mediated Apoptosis and Is Associated with Poor Survival. Cancer Research, 67, 3036-3042. http://dx.doi.org/10.1158/0008-5472.CAN-06-3755

[18] Yu, Y., Khan, J., Khanna, C., et al. (2004) Expression Profiling Identifies the Cytoskeletal Organizer Ezrin and the Developmental Homeoprotein Six-1 as Key Metastatic Regulators. Nature Medicine, 10, 175-181. http://dx.doi.org/10.1038/nm966

[19] Ng, K.T., Man, K., Sun, C.K., et al. (2006) Clinicopathological Significance of Homeoprotein Six1 in Hepatocellular Carcinoma. British Journal of Cancer, 95, 1050-1055. http://dx.doi.org/10.1038/sj.bjc.6603399

[20] Jin, A., Xu, Y., Liu, S., et al. (2013) Sineoculis Homeobox Homolog 1 Protein Overexpression as an Independent 
Biomarker for Pancreatic Ductal Adenocarcinoma. Experimental and Molecular Pathology, 96, 54-60. http://dx.doi.org/10.1016/j.yexmp.2013.11.003

[21] Iwanaga, R., Wang, C.A., Micalizzi, D.S., et al. (2012) Expression of Six1 in Luminal Breast Cancers Predicts Poor Prognosis and Promotes Increases in Tumor Initiating Cells by Activation of Extracellular Signal-Regulated Kinase and Transforming Growth Factor-Beta Signaling Pathways. Breast Cancer Research, 14, R100. http://dx.doi.org/10.1186/bcr3219

[22] Mimae, T., Okada, M., Hagiyama, M., et al. (2012) Upregulation of Notch2 and Six1 Is Associated with Progression of Early-Stage Lung Adenocarcinoma and a More Aggressive Phenotype at Advanced Stages. Clinical Cancer Research, 18, 945-955. http://dx.doi.org/10.1158/1078-0432.CCR-11-1946

[23] Reichenberger, K.J., Coletta, R.D., Schulte, A.P., et al. (2005) Gene Amplification Is a Mechanism of Six1 Overexpression in Breast Cancer. Cancer Research, 65, 2668-2675. http://dx.doi.org/10.1158/0008-5472.CAN-04-4286

[24] Patrick, A.N., Cabrera, J.H., Smith, A.L., et al. (2013) Structure-Function Analyses of the Human SIX1-EYA2 Complex Reveal Insights into Metastasis and BOR Syndrome. Nature Structural \& Molecular Biology, 20, 447-453. http://dx.doi.org/10.1038/nsmb.2505

[25] Krueger, A.B., Dehdashti, S.J., Southall, N., et al. (2013) Identification of a Selective Small-Molecule Inhibitor Series Targeting the Eyes Absent 2 (Eya2) Phosphatase Activity. Journal of Biomolecular Screening, 18, 85-96. http://dx.doi.org/10.1177/1087057112453936

[26] Qamar, L., Deitsch, E., Patrick, A.N., et al. (2012) Specificity and Prognostic Validation of a Polyclonal Antibody to Detect Six1 Homeoprotein in Ovarian Cancer. Gynecologic Oncology, 125, 451-457. http://dx.doi.org/10.1016/j.ygyno.2012.02.007

[27] Gao, J.J., Aksoy, B.A., Gross, B., et al. (2013) cBioPortal for Cancer Genomics. 2013: The cBioPortal for Cancer Genomics Is Developed and Maintained by the Computational Biology Center at Memorial Sloan-Kettering Cancer Center and the I-Vis (Information Visualization) Research Group of the Computer Engineering Department at Bilkent University.

[28] Micalizzi, D.S., Christensen, K.L., Jedlicka, P., et al. (2009) The Six1 Homeoprotein Induces Human Mammary Carcinoma Cells to Undergo Epithelial-Mesenchymal Transition and Metastasis in Mice through Increasing TGF-Beta Signaling. Journal of Clinical Investigation, 119, 2678-2690. http://dx.doi.org/10.1172/JCI37815

[29] Wang, C.A., Jedlicka, P., Patrick, A.N., et al. (2012) Six1 Induces Lymphangiogenesis and Metastasis via Upregulation of VEGF-C in Mouse Models of Breast Cancer. Journal of Clinical Investigation, 122, 1895-1906. http://dx.doi.org/10.1172/JCI59858

[30] Li, Z., Tian, T., Hu, X., et al. (2013) Six1 Mediates Resistance to Paclitaxel in Breast Cancer Cells. Biochemical and Biophysical Research Communications, 441, 538-543. http://dx.doi.org/10.1016/j.bbrc.2013.10.131

[31] Stashwick, C., Post, M.D., Arruda, J.S., et al. (2011) Surgical Risk Score Predicts Suboptimal Debulking or a Major Perioperative Complication in Patients with Advanced Epithelial Ovarian, Fallopian Tube, or Primary Peritoneal Cancer. International Journal of Gynecological Cancer, 21, 1422-1427. http://dx.doi.org/10.1097/IGC.0b013e31822c7704

[32] Farabaugh, S.M., Micalizzi, D.S., Jedlicka, P., et al. (2012) Eya2 Is Required to Mediate the Pro-Metastatic Functions of Six1 via the Induction of TGF-Beta Signaling, Epithelial-Mesenchymal Transition, and Cancer Stem Cell Properties. Oncogene, 31, 552-562.

[33] Behbakht, K., Sill, M.W., Darcy, K.M., et al. (2011) Phase II Trial of the mTOR Inhibitor, Temsirolimus and Evaluation of Circulating Tumor Cells and Tumor Biomarkers in Persistent and Recurrent Epithelial Ovarian and Primary Peritoneal Malignancies: A Gynecologic Oncology Group Study. Gynecologic Oncology, 123, 19-26. http://dx.doi.org/10.1016/j.ygyno.2011.06.022 